\title{
A Comparison of the Surface Properties of CAD/CAM and Conventional Polymethylmethacrylate (PMMA)
}

\author{
Al-Dwairi, Ziad N ; Tahboub, Kawkab Y ; Baba, Nadim Z ; Goodacre, Charles J ; Özcan, Mutlu
}

\begin{abstract}
Purpose To compare surface properties of 2 brands of pre-polymerized resin blocks for complete dentures (CAD/CAM PMMA) to conventional heat-polymerized PMMA. Materials and Methods A total of 45 rectangular specimens $(25 \times 25 \times 3 \mathrm{~mm})$ were fabricated from 3 brands of PMMA (n = 15/group): AvaDent CAD/CAM PMMA, Tizian-Schütz CAD/CAM PMMA, Meliodent conventional PMMA. Specimens were examined for wettability using the sessile drop method, surface roughness using a digital contact profilometer, and microhardness using Vickers hardness number. Statistical analysis was performed using one-way ANOVA and Tukey pairwise multiple comparisons. p-Values of 0.05 were considered significant. Results AvaDent specimens demonstrated the highest mean contact angle $(72.87 \pm$ $\left.48^{\circ}\right)$ and the highest mean Vickers hardness number $(20.62 \pm 0.33)$. The conventional heat-polymerized specimens showed the highest mean surface roughness $(0.22 \pm 0.071 \mathrm{~m})$. Tizian-Schütz specimens showed the lowest mean surface roughness $(0.12 \pm 0.02 \mathrm{~m})$. Conclusions As CAD/CAM PMMA groups exhibited significantly more favorable surface properties in comparison to the conventional heat-polymerized groups, CAD/CAM dentures are expected to be more durable. Different brands of CAD/CAM PMMA may have inherent variations in surface properties.
\end{abstract}

DOI: https://doi.org/10.1111/jopr.13033

Posted at the Zurich Open Repository and Archive, University of Zurich

ZORA URL: https://doi.org/10.5167/uzh-183156

Journal Article

Accepted Version

Originally published at:

Al-Dwairi, Ziad N; Tahboub, Kawkab Y; Baba, Nadim Z; Goodacre, Charles J; Özcan, Mutlu (2019). A Comparison of the Surface Properties of CAD/CAM and Conventional Polymethylmethacrylate (PMMA). Journal of Prosthodontics, 28(4):452-457.

DOI: https://doi.org/10.1111/jopr.13033 
Title

A Comparison of the Surface Properties of CAD/CAM and Conventional

Polymethylmethacrylate (PMMA)

\section{Running Title}

Surface Properties of CAD/CAM and PMMA

\section{Authors}

Ziad Al-Dwairi, BDS, PhD, MFDSRCS (England), MFDSRCPS (Glasgow), MFDSRCS

(Edinbrugh), MFGDP (UK), FIADFE, FICD, FADI, FPFA, FICCDE, ${ }^{1}$ Kawkab Y. Tahboub, BDS, MClinDent, ${ }^{1}$ Nadim Z. Baba, DMD, MSD, FACP ${ }^{2}$ Charles J. Goodacre, DDS, MSD, FACP $^{2}{ }^{2} \&$ Mutlu Özcan, Dr. med. dent., PhD, FADM, FICD, FDS, RCPS (Glasgow) ${ }^{3}$

\section{Institutions}

${ }^{1}$ Department of Prosthodontics, Faculty of Dentistry, Jordan University of Science and Technology (JUST), Irbid, Jordan

${ }^{2}$ Advanced Specialty Education Program in Prosthodontics, Loma Linda University, School of Dentistry, Loma Linda, CA

${ }^{3}$ University of Zurich, Head of Dental Materials Unit, Center for Dental and Oral Medicine, Clinic for Fixed and Removable Prosthodontics and Dental Materials Science, Zurich,

Switzerland

Correspondence: Ziad Al-Dwairi, Professor, Department of Prosthodontics, Faculty of

Dentistry, Jordan University of Science and Technology (JUST), P.O. Box 3030 code 22110, Irbid, Jordan. E-mail: Ziadd@just.edu.jo.

Accepted February 3, 2019

This study was supported by a grant (\#240/2016) from the Deanship of Scientific Research, Jordan University of Science and Technology

The authors deny any conflicts of interest related to the current study.

This article has been accepted for publication and undergone full peer review but has not been through the copyediting, typesetting, pagination and proofreading process, which may lead to differences between this version and the Version of Record. Please cite this article as doi: 10.1111/jopr.13033.

This article is protected by copyright. All rights reserved. 


\begin{abstract}
Purpose: To compare surface properties of 2 brands of pre-polymerized resin blocks for complete dentures (CAD/CAM PMMA) to conventional heat-polymerized PMMA.

Materials and Methods: A total of 45 rectangular specimens $(25 \times 25 \times 3 \mathrm{~mm})$ were fabricated from 3 brands of PMMA ( $\mathrm{n}=$ 15/group): AvaDent CAD/CAM PMMA, TizianShütz CAD/CAM PMMA, Meliodent conventional PMMA. Specimens were examined for wettability using the sessile drop method, surface roughness using a digital contact profilometer, and microhardness using Vickers hardness number. Statistical analysis was performed using one-way ANOVA and Tukey pairwise multiple comparisons. $P$-values of $\leq$ 0.05 were considered significant.
\end{abstract}

Results: AvaDent specimens demonstrated the highest mean of contact angle $\left(72.87 \pm 48^{\circ}\right)$ and the highest mean of Vickers hardness number $(20.62 \pm 0.33)$. The conventional heatpolymerized specimens showed the highest mean of surface roughness $(0.22 \pm 0.071 \mu \mathrm{m})$. Tizian-Schütz specimens showed the lowest mean of surface roughness $(0.12 \pm 0.02 \mu \mathrm{m})$.

Conclusions: As CAD/CAM PMMA groups exhibited significantly more favorable surface properties in comparison to the conventional heat-polymerized groups, CAD/CAM dentures are expected to be more durable. Different brands of CAD/CAM PMMA may have inherent variations in surface properties.

Keywords: CAD/CAM; complete denture; dentures; PMMA; polymethylmethacrylate; surface properties.

Complete dentures still represent the only convenient treatment option for a considerable percentage of patients. ${ }^{1,2}$ Therefore, the ideal denture base material should have superior surface and mechanical properties. ${ }^{3}$ Walter Wright introduced acrylic resin - 
polymethylmethacrylate (PMMA) - to the market in 1936. It became the most popular denture base material ${ }^{4,5}$ and gained increased popularity due to its ease of handling and manipulation, lack of toxicity, good esthetic results, adequate strength, ease of reparability, stability in the oral environment, low solubility, reasonable cost, and low water sorption. ${ }^{6,7}$ However, the mechanical properties of PMMA have been considered inadequate. ${ }^{4,8}$ Among the common drawbacks of PMMA are dimensional changes, susceptibility to fracture, residual monomers, and increased risk of denture-associated infections. ${ }^{8,9}$ In addition, there is a possibility of surface and subsurface voids, which can not only jeopardize the mechanical properties of the processed denture but also compromise esthetic and hygienic results. ${ }^{10}$

Surface characteristics of acrylic dentures such as roughness, hardness, and wettability have been reported to be key players in denture-associated stomatitis., ${ }^{9,113}$ Surface roughness has been described as "little indentations or irregularities that characterizes a surface and has its influence on wetting, quality of adhesion, and brightness of that surface." ${ }^{14}$ Rough surfaces tend to induce halitosis ${ }^{5}$ and are considered more vulnerable to discoloration than smooth surfaces, thereby reducing patient comfort. ${ }^{14}$ As microbial adhesion and colonization usually occur on nonshedding surfaces, ${ }^{15}$ dental prostheses need to have smooth surfaces to minimize the retention of plaque and microorganisms. ${ }^{11,14}$ To decrease the accumulation and colonization of microorganisms, the surface roughness of dental prostheses should not exceed a threshold of $0.2 \mu \mathrm{m} .^{1,5,16}$ Studies reported that a 0.2 $\mu \mathrm{m}$ roughness threshold can be achieved by common laboratory and chairside finishing and polishing procedures. ${ }^{17}$ Therefore, adequate finishing and polishing of dental prostheses, including dentures, are mandatory to minimize prosthesis surface roughness. ${ }^{16}$ Zissis et $\mathrm{al}^{17}$ evaluated the surface roughness of commercially available denture base materials, including soft and hard relining materials, and reported the overall surface roughness to be between 0.7 and $7.6 \mu \mathrm{m}$. 
Surface wettability is an indicator of the ability of saliva and other liquids to easily spread over a surface and reflects the amenability to allow or prevent adherence of fluids to prosthetic surfaces and dental materials. ${ }^{18}$ Ultimate wettability, for example, is needed for fixed restoration cementation and retention of removable dentures. ${ }^{19}$ On the other hand, wettability can be troublesome in favoring staining, microorganisms, and plaque adhesion on oral prostheses. ${ }^{16,19,20}$

Surface hardness is defined as "the ability of a material's surface to resist permanent penetration or indentation. ${ }^{21}$ In addition to being sensitive to monomer levels, it has been reported that there is a correlation between surface hardness and a material's mechanical properties. ${ }^{3}$ For example, the amenability of acrylic-polymer to degradation makes it vulnerable to fracture and aggravates the chance of plaque, microorganism, and pigment retention, eventually jeopardizing the denture base longevity. ${ }^{22}$

Computer-aided design/computer-aided manufacturing (CAD/CAM) techniques have expanded recently to embrace the fabrication of complete dentures, record bases, immediate dentures, and implant-supported overdentures in 2 clinical appointments. ${ }^{23}$ As CAD/CAM dentures are milled from pre-polymerized PMMA billets that are polymerized under high temperatures and pressure values, $\mathrm{CAD} / \mathrm{CAM}$ dentures are reported to be less porous, and consequently, less likely to harbor virulent microorganisms such as Candida albicans, which will be less able to adhere to the surface of digital dentures. ${ }^{24}$ Accordingly, CAD/CAM dentures provide a promising treatment option for patients at risk of Candida fungal infection; however, the authors know of no published reports that have investigated the surface properties of CAD/CAM PMMA. The null hypotheses of the study were that no differences would be found between the surface properties of CAD/CAM PMMA and conventional heat-polymerized PMMA nor between different brands of available CAD/CAM PMMA. 


\section{MATERIALS AND METHODS}

Two brands of CAD/CAM PMMA billets were used in this study: AvaDent PMMA billets (Global Dental Science, Scottsdale, AZ) and Tizian Blank PMMA (Shütz Dental, Rosbach vor der Höhe, Germany). Four billets (98 mm diameter $\times 25 \mathrm{~mm}$ thick) were needed from each brand to mill the CAD/CAM PMMA specimens.

A plexiglass (Year Long Industrial Co. Ltd, Tainan City, Taiwan) specimen measuring $25 \times 25 \times 3 \mathrm{~mm}$ was sprayed with a contrast spray (mega Okklusions Spray EXACT; megadental Gmbh, Büdingen, Germany), stabilized on a custom-made stone base, and mounted in Ceramill map $400 \mathrm{CAD} / \mathrm{CAM}$ scanner (Amann Girrbach AG, Koblach, Austria). The digital image of the scanned specimen was processed using Ceramill mind1.0 software (Exocad GmbH, University of Chicago, IL).

PMMA billets were milled according to the provided design using TIZIAN Cut 5 Smart Plus open CAD/CAM milling system, (Shütz Dental). Thereafter, milled specimens were cut from the billets and finished using tungsten carbide acrylic burs (Edenta, Au, Switzerland) and silicon carbide papers (Schmirgelleinen; megadental). The specimens were further polished using rubber acrylic burs (Edenta), pumice (Shera, Lemförde, Germany), and rouge (Dialux, Paris, France). Polishing was performed for one surface only while the other surface remained untouched in order to mimic denture tissue surfaces as much as possible. ${ }^{9}$ All specimens were prepared and polished by the same operator. Specimen dimensions were verified using a digital caliper (Mitutoyo Corp., Tokyo, Japan). Specimens were stored in distilled water for 48 hours to eliminate residual monomers. ${ }^{9}$ 


\section{Conventional heat-polymerized PMMA specimen fabrication}

CAD/CAM PMMA specimens measuring $25 \times 25 \times 3 \mathrm{~mm}$ were coated with 2 layers of Vaseline (Beirut Co., Damascus, Syria) then invested in vacuum-mixed type III dental stone (Elite Model; Zhermack, Badia Polesine, Italy) and a vacuum-mixed 50:50 mixture of dental stone and dental plaster (Al khayyat dental plaster, Yanbu, Saudi Arabia). Flasking was done in a two-part mold using a Hanau Varsity Flask (Hanau Engineering Co., Buffalo, NY). The flasks were opened, and the PMMA patterns were removed. The surfaces of the rectangular cavities were sealed with 2 coats of Cold Mold Seal (PSP, Kent, UK) sealant. Heatpolymerized acrylic resin (Meliodent, Heraeus Kulzer, Hanau Germany) powder and liquid were proportioned and mixed according to manufacturer instructions. The dough was packed under pressure then polymerized using a short curing cycle in a thermostatically controlled water bath (Type 5518; KaVo EWL, Biberach, Germany), according to manufacturer instructions.

Excess acrylic was trimmed and specimens were finished and polished exactly as done for the CAD/CAM PMMA specimens. Specimen dimensions were verified using a digital caliper (Mitutoyo Corp.). Likewise, specimens were stored in distilled water for 48 hours to minimize residual monomers. ${ }^{25}$

For each study group, 15 specimens measuring $25 \times 25 \times 3 \mathrm{~mm}$ were used to perform the following surface tests (Fig 1).

\section{Surface wettability}

The sessile drop method was used to measure the angle formed by distilled water on the PMMA surface. ${ }^{26}$ A $20-\mu 1$ distilled water drop was delivered from a micropipette (Transferpette S; Sigma Aldrich, Darmstadt, Germany) on the polished surface of a This article is protected by copyright. All rights reserved. 
horizontally placed specimen on a previously tested horizontal bench. ${ }^{27}$ The water drop was left to spread for 20 seconds, and at that moment, a Canon EOS 60D camera (Canon, Melville, NY) with a 105 mm Sigma micro-lens (Sigma Corp., Kanagawa, Japan) was used to capture an image. The camera was fixed to its tripod throughout the procedure. Specimens were placed on a previously marked position, which guaranteed fixed setting each time. The image was then imported and analyzed using AutoCAD 2010 software. The angle (ø) between the solid line of the specimen and the tangent to the water drop was measured on the right and left sides, and the average was recorded. ${ }^{9}$

\section{Surface roughness}

After bench drying, the specimens were tested for surface roughness using a digital contact profilometer (RT-10, SM S.R.L, Italy) with a resolution of $0.001 \mu \mathrm{m}$ and a total measurement length of $0.8 \mathrm{~mm}$. Four Ra readings on different areas with similar positions on each polished surface of the specimens were taken and the average was calculated. ${ }^{9}$

\section{Surface hardness}

Vickers hardness number (VHN) was used to determine the surface hardness for the specimens directly after removal from the distilled water. A Micro Hardness Tester (Model MHT-1, No.8621; Matsuzawa Seiki Co. LTD., Tokyo, Japan) was used with a square-based pyramid indenter under a $300 \mathrm{~g}$ load at 15 -second dwell time. ${ }^{9}$ Three indentations were performed for each specimen. Afterwards the pyramids were analyzed, and the resulting diagonals were measured to calculate the VHN (Fig 2). The average for the three VHNs was calculated. 


\section{Statistical analysis}

(1)

Individual contact angle, surface roughness, and VHN values were calculated and tabulated. Minitab 17 computer software (Minitab Inc. State College, PA) was used to calculate the means and the standard deviations for each test. Afterward, one-way ANOVA was used to determine whether significant differences existed among the study groups (AvaDent, TizianShcütz, and the conventional heat-polymerized groups), followed by Tukey-pairwise multiple comparisons. A $P$ value of $\leq 0.05$ was considered significant. The non-parametric test (Kruskal-Wallis) was used in case considerable variations in values of surface properties were noticed.

\section{RESULTS}

\section{Contact angles}

Means and standard deviations of average contact angles are summarized in Table 1. AvaDent specimens demonstrated the highest mean contact angle $\left(72.87 \pm 4.83^{\circ}\right)$, followed by Tizian-Shcütz $\left(69.53 \pm 3.87^{\circ}\right)$. The conventional heat-polymerized group showed the lowest mean of contact angle $\left(65.97 \pm 4.67^{\circ}\right)$. The difference in mean angles between the AvaDent group and the conventional heat-polymerized group was statistically significant $(P<$ $0.001, F=8.92$ ). The mean contact angles of the Tizian-Shcütz group was not statistically significant from the AvaDent group $(P=0.115)$, or from the conventional heat-polymerized group $(P=0.086)($ Table 2$)$. 


\section{Surface roughness (Ra values)}

Conventional heat-polymerized PMMA (Table 1) showed the highest mean surface roughness $(0.22 \pm 0.07 \mu \mathrm{m})$, followed by AvaDent $(0.16 \pm 0.03 \mu \mathrm{m})$. The Tizian-Shcütz group showed the lowest mean of surface roughness $(0.12 \pm 0.02 \mu \mathrm{m})$. The decrease in the means of the surface roughness between the three tested groups was statistically significant $(P<0.05, \mathrm{~F}=18.03)($ Table 2$)$.

\section{Surface hardness}

The highest mean of VHN was recorded for the AvaDent group (20.62 \pm 0.33$)$ followed by the Tizian-Schütz group $(19.80 \pm 1.08)$ and the conventional heat-polymerized group $(18.09$ \pm 0.31 ) (Table 1). Both Kruskal-Wallis and ANOVA methods showed that the 3 groups differed in hardness means. Tukey pairwise comparisons revealed that these differences are statistically significant. $(P<0.05 ; \mathrm{F}=53.72)$ (Table 2$)$.

\section{DISCUSSION}

Manufacturers claim that $\mathrm{CAD} / \mathrm{CAM}$ dentures possess superior fit, surface characteristics, and mechanical properties in comparison to conventional heat-polymerized dentures. The null hypotheses of this study that no significant differences would be found in surface properties between CAD/CAM PMMA and conventional heat-polymerized PMMA nor between different brands of CAD/CAM PMMA was rejected; CAD/CAM PMMA demonstrated significant superiority in surface wettability, surface roughness, and surface hardness. Different CAD/CAM PMMA brands might have variable surface properties. Improved surface properties in the $\mathrm{CAD} / \mathrm{CAM}$ groups may be attributed to the unique processing method of the CAD/CAM PMMA billets in which high temperatures and pressure values are used for CAD/CAM PMMA polymerization. ${ }^{14}$ 
The calculated mean of contact angles of the conventional heat-polymerized specimens in this study $\left(65.97^{\circ}\right)$ was close to the mean angle obtained by Al-Dwairi et al in their 2012 study $\left(64.6^{\circ}\right) .{ }^{9}$ Zissis et $\mathrm{al}^{26}$ measured the equilibrium contact angles of different acrylic denture base materials in addition to soft and hard relining materials and reported that the range of contact angles was between 63.9 and $81.0^{\circ}$. All contact angles obtained in this study were in line with the results of the aforementioned study. Murat et $\mathrm{al}^{28}$ reported a higher contact angle, and consequently, higher hydrophobicity of conventional heat-cured PMMA when compared to CAD/CAM PMMA. The results they obtained were attributed to the effect of thermal cycling.

On the other hand, Steinmassl et $\mathrm{al}^{29}$ reported that CAD/CAM PMMA were significantly more hydrophilic than their heat-polymerized PMMA counterparts. The increased values of contact angles among the CAD/CAM PMMA groups might be attributed to inherent characteristic features of their surfaces. It has been reported that surface energy can be affected by the surface topography, charge, and chemical composition as well as by the acquired salivary pellicle..$^{20}$ Increased hydrophobicity ${ }^{16,19,20}$ of CAD/CAM PMMA as well as PMMA water sorption ${ }^{10}$ might have an impact on the amenability of CAD/CAM dentures to retain stains, plaque, and microorganisms. The contact angle is the product of the balance between interfacial and surface forces. Small contact angles are associated with more water spread, increased wettability, increased hydrophilicity of the PMMA surface, and therefore increased retention of removable dentures.

Properly polished acrylic dentures and smooth dentures are more likely to succeed intraorally, given that denture base roughness has been related to its vulnerability to retain stains, plaque, and microorganisms. ${ }^{30}$ Because surface roughness of denture base materials was reported to be influenced by the inherent properties of the material itself, polishing 
techniques, and the manual skills of the operator, one operator was responsible for preparing and finishing all the specimens in this study.

Recorded roughness values of the test groups in the current study were lower than the range reported by Zissis et al. ${ }^{17}$ Previous studies reported significant increase in plaque retention and microorganism adherence to restorative materials when the $R_{a}$ of these materials exceeds $0.2 \mu \mathrm{m} .{ }^{20}$ Lower Candida adherence is expected for AvaDent and TizianShcütz groups, which demonstrated $\mathrm{R}_{\mathrm{a}}$ values around $0.1 \mu \mathrm{m}$. Both of the CAD/CAM PMMA groups showed lower surface roughness values in comparison to the conventional heatpolymerized group $(P<0.05)$, which supports Bidra et al's claim that CAD/CAM PMMA has better surface properties, less porosity, and eventually less microbial adherence. Likewise, enhanced surface characteristics of CAD/CAM PMMA might be attributed to the unique manufacturing process of these materials; reduced levels of residual monomers as well as the polymerization method involved in PMMA manufacturing were previously reported to contribute to surface roughness alteration. ${ }^{32}$ The results of the present study support Murat et al's results ${ }^{28}$ of lower $\mathrm{R}_{\mathrm{a}}$ values for the CAD/CAM PMMA group using a contact type profilometer and the results of Steinmassl et al, ${ }^{29}$ who tested different complete dentures of variable $\mathrm{CAD} / \mathrm{CAM}$ PMMA brands and compared them to conventional dentures and reported significant lower roughness values for the CAD/CAM groups.

Srinivasan et $\mathrm{al}^{33}$ recently reported no statistical difference between surface roughness of conventionally cured PMMA and CAD/CAM PMMA; however, in their study they used manual table saws to cut the specimens, instead of a milling system, which might have an effect on comparing surface roughness values. Moreover, a non-contact laser profilometer was used to detect $\mathrm{R}_{\mathrm{a}}$ values in the aforementioned study. Arslan et $\mathrm{al}^{34}$ recently found that the hydrophobicity of CAD/CAM PMMA-based polymers was higher than the conventional 
heat-polymerized PMMA, whereas the CAD/CAM PMMA-based polymers had $\mathrm{R}_{\mathrm{a}}$ values similar to the conventional PMMA.

In the present study, CAD/CAM PMMA groups exhibited higher surface hardness than the conventional heat-polymerized group did, which might support the manufacturer's claim of lower levels of residual monomers in CAD/CAM PMMA. In 2012, Farina et al reported that homogenous heating of PMMA yielded higher monomer conversion, minimized the plasticizing effect of residual monomers, and consequently increased surface hardness. ${ }^{22}$

Although the results of the present study reported differences in surface properties between CAD/CAM and conventional dentures, the choice between digitally milled and conventional dentures may also be influenced by processing time and cost; however, a recent survey in US dental schools evaluated digital dental fabrication in pre- and postdoctoral education reported found that in US programs, the percentage of CAD/CAM complete denture fabrication out of the total number of fabricated complete dentures approached $10 \%$, and the majority of respondents program directors are planning to include CAD/CAM dentures to their curricula within a period of 1 to 4 years. Accordingly, the anticipated spread of $\mathrm{CAD} / \mathrm{CAM}$ dentures will positively raise the level of education, investigation, and the evaluation of the different clinical scenarios since these dentures are entirely digitally manufactured. ${ }^{35}$

\section{CONCLUSIONS}

1- CAD $\backslash C A M$ PMMA groups exhibited significantly higher surface hardness and hydrophobicity in comparison to the conventional heat-polymerized group. 2- Different CAD/CAM PMMA brands might have variable surface hardness, surface roughness, and wettability. 
3- The AvaDent CAD/CAM PMMA group demonstrated the highest surface hardness

(VHN), while the Tizian-Schütz group registered the lowest $\mathrm{R}_{\mathrm{a}}$ value for surface roughness.

No significant differences among the 2 groups were found for contact angle.

\section{REFERENCES}

1.Paulino MR, Alves LR, Gurgel BC et al: Simplified versus traditional techniques for complete denture fabrication: A systematic review. J Prosthet Dent 2015;113:12-16 2.Saponaro PC, Yilmaz B, Heshmati RH, et al: Clinical performance of CAD-CAMfabricated complete dentures: A cross-sectional study. J Prosthet Dent 2016;116:431-435

3. Hae-Hyoung LE, Chung-Jae LE, Asaoka K: Correlation in the mechanical properties of acrylic denture base resins. Dent Mater J 2012; 31:157-164

4. Kanazawa M, Inokoshi M, Minakuchi S, et al: Trial of a CAD/CAM system for fabricating complete dentures. Dent Mater J 2011;30:93-96

5. Mahross HZ, Mohamed MD, Hassan AM, et al: Effect of cigarette smoke on surface roughness of different denture base materials. J Clin Diagn Res 2015;9:39-42

6. Babu MR, Rao CS, Ahmed ST, et al: A comparative evaluation of the dimensional accuracy of heat polymerised PMMA denture base cured by different curing cycles and clamped by RS technique and conventional method-An In-vitro study. J Int Oral Health $2014 ; 6: 68-75$

7. Hashem M, Alsaleem SO, Assery MK, et al: A comparative study of the mechanical properties of the light-cure and conventional denture base resins. Oral Health Dent Manag $2014 ; 13: 311-315$

8. Takahashi Y, Yoshida K, Shimizu H: Fracture resistance of maxillary complete dentures subjected to long-term water immersion. Gerodontol 2012;29:1086-1091 
9. AL-Dwairi ZN, Al-Quraan F, AL-Omari OY: The effect of antifungal agents on surface properties of poly (methyl methacrylate) and its relation to adherence of Candida albicans. J Prosthodont Res 2012;56:272-280

10. Anusavice KJ, Shen C, Rawls HR (eds): Phillips' Science of Dental Materials (ed 12). Philadelphia, Saunders, 2013

11. Rodriguez LS, Paleari AG, Giro G, et al: Chemical characterization and flexural strength of a denture base acrylic resin with monomer 2-tert-butylaminoethyl methacrylate. J Prosthodont 2013;22:292-297

12. Azuma A, Akiba N, Minakuchi S: Hydrophilic surface modification of acrylic denture base material by silica coating and its influence on Candida albicans adherence. J Med Dent Sci 2012;59:1-7

13. Susewind S, Lang R, Hahnel S: Biofilm formation and Candida albicans morphology on the surface of denture base materials. Mycoses 2015;58:719-727

14. Cortés-Sandoval G, Martínez-Castañón GA, Patiño-Marín N, et al: Surface roughness and hardness evaluation of some base metal alloys and denture base acrylics used for oral rehabilitation. Mater Lett 2015;144:100-105

15. Peracini A, Davi LR, de Queiroz Ribeiro N, et al: Effect of denture cleansers on physical properties of heat-polymerized acrylic resin. J Prosthodont Res 2010;54:78-83 16. Kuhar M, Funduk N: Effects of polishing techniques on the surface roughness of acrylic denture base resins. J Prosthet Dent 2005;93:76-85

17. Zissis AJ, Polyzois GL, Yannikakis SA, et al: Roughness of denture materials: A comparative study. Int J Prosthodont 2000;13:136-140

18. Jin NY, Lee HR, Lee H, et al: Wettability of denture relining materials under water storage over time. J Adv Prosthodont 2009;1:1-5 
19. Combe EC, Owen BA, Hodges JS: A protocol for determining the surface free energy of dental materials. Dent Mater J 2004;20:262-268

20. Foggi CC, Machado AL, Zamperini CA, et al: Effect of surface roughness on the hydrophobicity of a denture-base acrylic resin and Candida albicans colonization. J Investig Clin Dent 2016;7:141-148

21. Abdulwahhab SS: High-impact strength acrylic denture base material processed by autoclave. J Prosthodont Res 2013;57:288-293

22. Farina AP, Cecchin D, Soares RG, et al: Evaluation of Vickers hardness of different types of acrylic denture base resins with and without glass fibre reinforcement.

Gerodontology 2012;29:155-160

23. Baba NZ, AlRumaih HS, Goodacre BJ, et al: Current techniques in CAD/CAM denture fabrication. Gen Dent 2016;64:23-28

24. A-Fouzan A, Al-Mejrad LA, Albarrag AM: Adherence of Candida to complete denture surfaces: A comparison of conventional and CAD/CAM complete dentures. J Adv Prosthodont 2017;9:402-408

25. Qian K, Pan H, Li Y, et al: Time-related surface modification of denture base acrylic resin treated by atmospheric pressure cold plasma. Dent Mater J 2016;35:97-103

26. Zissis A, Yannikakis S, Jagger RG, et al: Wettability of denture materials. Quintessence Int 2001;32:456-462

27. Puri G, Berzins DW, Dhuru VB, et al: Effect of phosphate group addition on the properties of denture base resins. J Prosthet Dent 2008;100:302-308 
28. Murat S, Alp G, Alatal C, et al: In vitro evaluation of adhesion of Candida albicans on CAD/CAM PMMA-based polymers. J Prosthodont 2018 Jul 1. doi:

10.1111/jopr.12942. [Epub ahead of print]

29. Steinmass1 O, Dumfahrt H, Grunert I, et al: Influence of CAD/CAM fabrication on denture surface properties. J Oral Rehabil 2018;45:406-413

30. Gungor H, Gundogdu M, Duymus ZY: Investigation of the effect of different polishing techniques on the surface roughness of denture base and repair materials. J Prosthet Dent 2014;112:1271-1277

31. Bidra AS, Taylor TD, Agar JR: Computer-aided technology for fabricating complete dentures: Systematic review of historical background, current status, and future perspectives. J Prosthet Dent 2013:109:361-366

32. Machado AL, Giampaolo ET, Vergani CE, et al: Changes in roughness of denture base and reline materials by chemical disinfection or microwave irradiation: Surface roughness of denture base and reline materials. J Appl Oral Sci 2011;19:521-528

33. Srinivasan M, Gjengedal H, Cattani-Lorente M, et al: CAD/CAM milled complete removable dental prostheses: An in vitro evaluation of biocompatibility, mechanical properties, and surface roughness. Dent Mater J 2018;37:526-533

34. Arslan M, Murat S, Alp G, et al: Evaluation of flexural strength and surface properties of prepolymerized CAD/CAM PMMA-based polymers used for digital 3D complete dentures. Int J Comput Dent 2018;21:31-40

35. Fernandez MA, Nimmo A, Behar-Horenstein LS: Digital denture fabrication in preand postdoctoral education: A Survey of US Dental Schools. J Prosthodont 2016;25:8390 
Table 1: Means and standard deviations for the performed tests

\begin{tabular}{|l|l|l|c|c|c|c|}
\hline & \multicolumn{2}{|c|}{ AvaDent } & \multicolumn{2}{c|}{ Schütz } & \multicolumn{2}{c|}{$\begin{array}{c}\text { Conventional heat- } \\
\text { polymerized }\end{array}$} \\
\cline { 3 - 8 } & Mean & $\begin{array}{l}\text { Standard } \\
\text { deviation }\end{array}$ & Mean & $\begin{array}{l}\text { Standard } \\
\text { deviation }\end{array}$ & Mean & $\begin{array}{l}\text { Standard } \\
\text { deviation }\end{array}$ \\
\hline $\begin{array}{l}\text { Contact angle } \\
\text { (degrees) }\end{array}$ & 72.87 & 4.83 & 69.53 & 3.87 & 65.97 & 4.67 \\
\hline
\end{tabular}

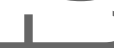

\begin{tabular}{|c|c|c|c|c|c|c|}
\hline & $\begin{array}{r}\mathbf{A} \\
\text { conve } \\
\text { po }\end{array}$ & $\begin{array}{l}\text { ent \& } \\
\text { onal heat- } \\
\text { lerized }\end{array}$ & $\begin{array}{r}\text { Con } \\
\text { polym }\end{array}$ & $\begin{array}{l}\text { ional heat } \\
\text { ed \& Tizian- } \\
\text { hütz }\end{array}$ & $\begin{array}{r}\text { Tizian } \\
\text { Av }\end{array}$ & $\begin{array}{l}\text { chütz \& } \\
\text { Dent }\end{array}$ \\
\hline & t-value & p-value & t-value & p-value & t-value & p-value \\
\hline $\begin{array}{l}\text { Surface } \\
\text { wettability }\end{array}$ & -4.22 & $<0.001$ & 2.18 & 0.086 & -2.04 & 0.115 \\
\hline $\begin{array}{l}\text { Surface } \\
\text { roughness }\end{array}$ & 3.50 & 0.003 & -6.00 & $<0.001$ & -2.65 & 0.031 \\
\hline $\begin{array}{l}\text { Surface } \\
\text { hardness }\end{array}$ & -10.14 & $<0.001$ & 6.93 & $<0.001$ & -3.21 & 0.007 \\
\hline
\end{tabular}

Table 2: P-values and t-values for the performed tests 


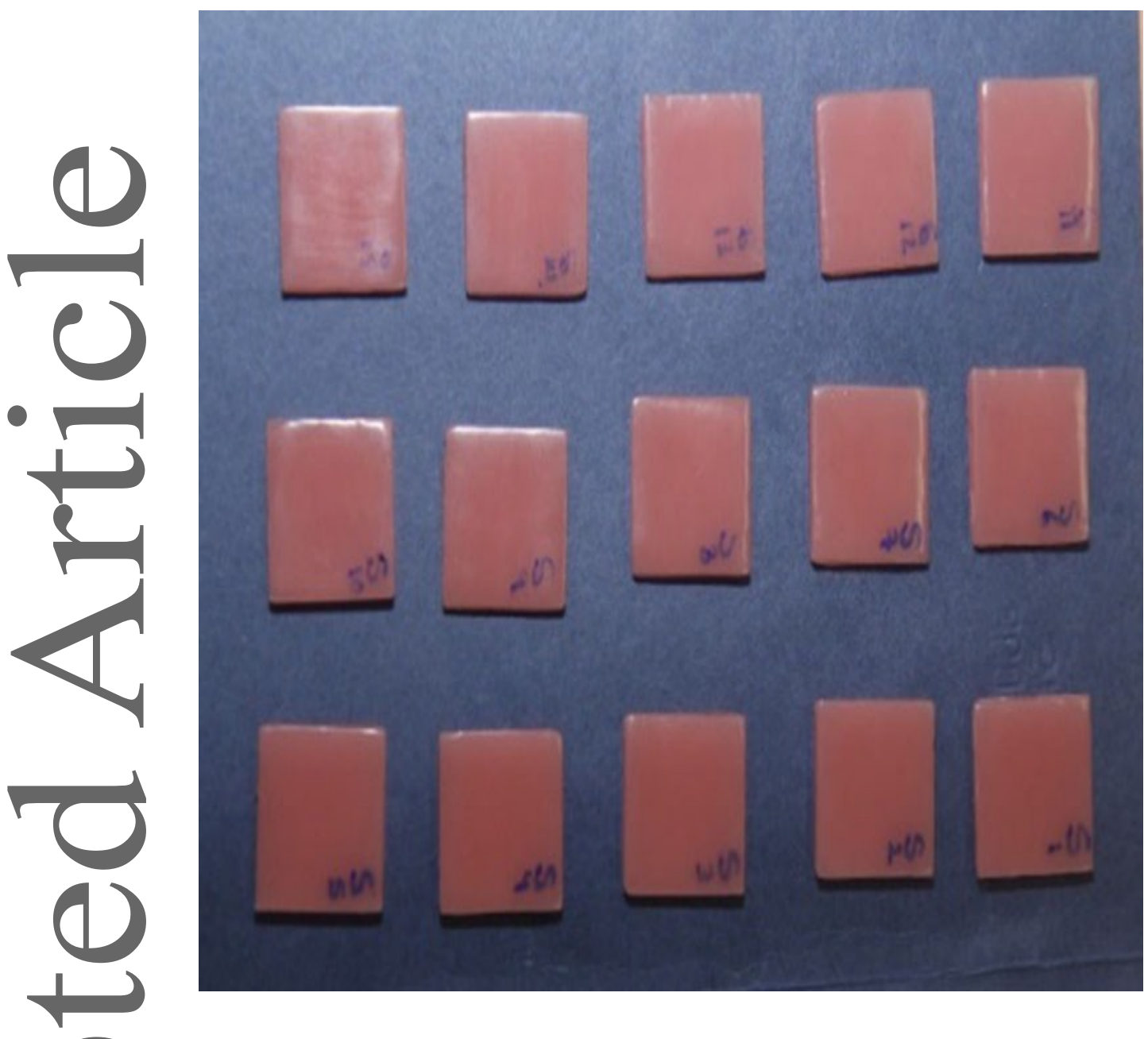

Figure 1 (A) AvaDent specimens 


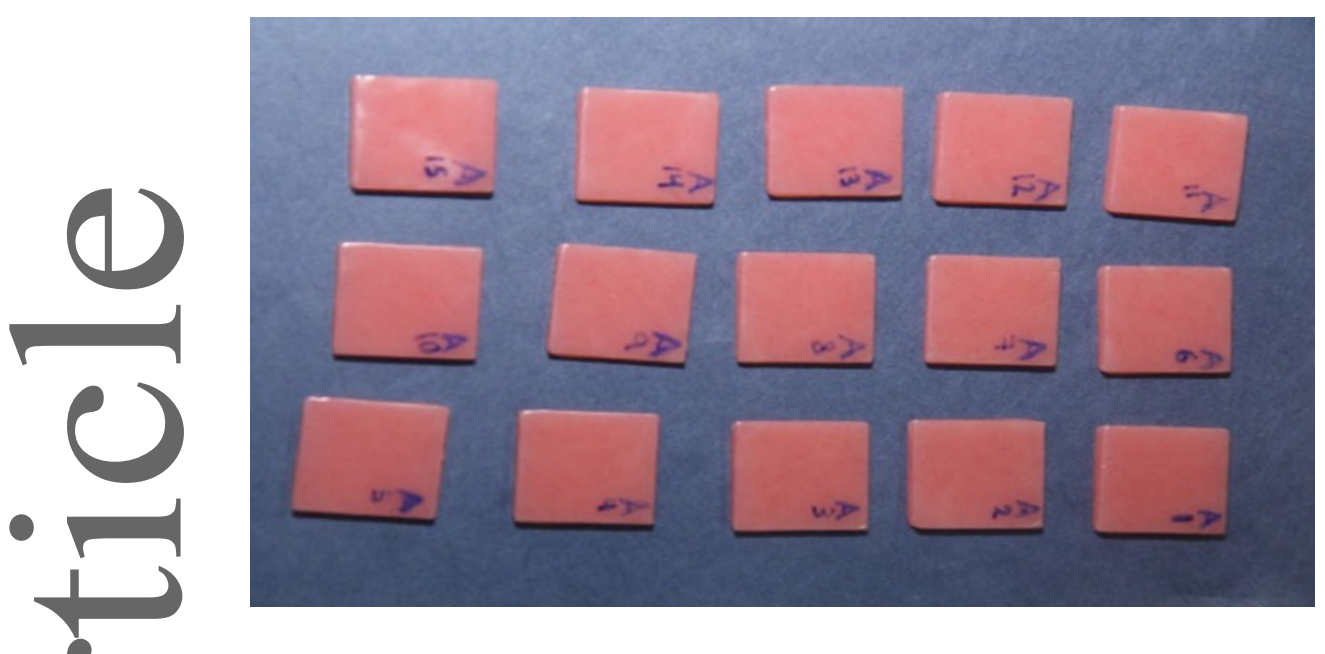

Figure 1 (B) Tizian-Schütz specimens

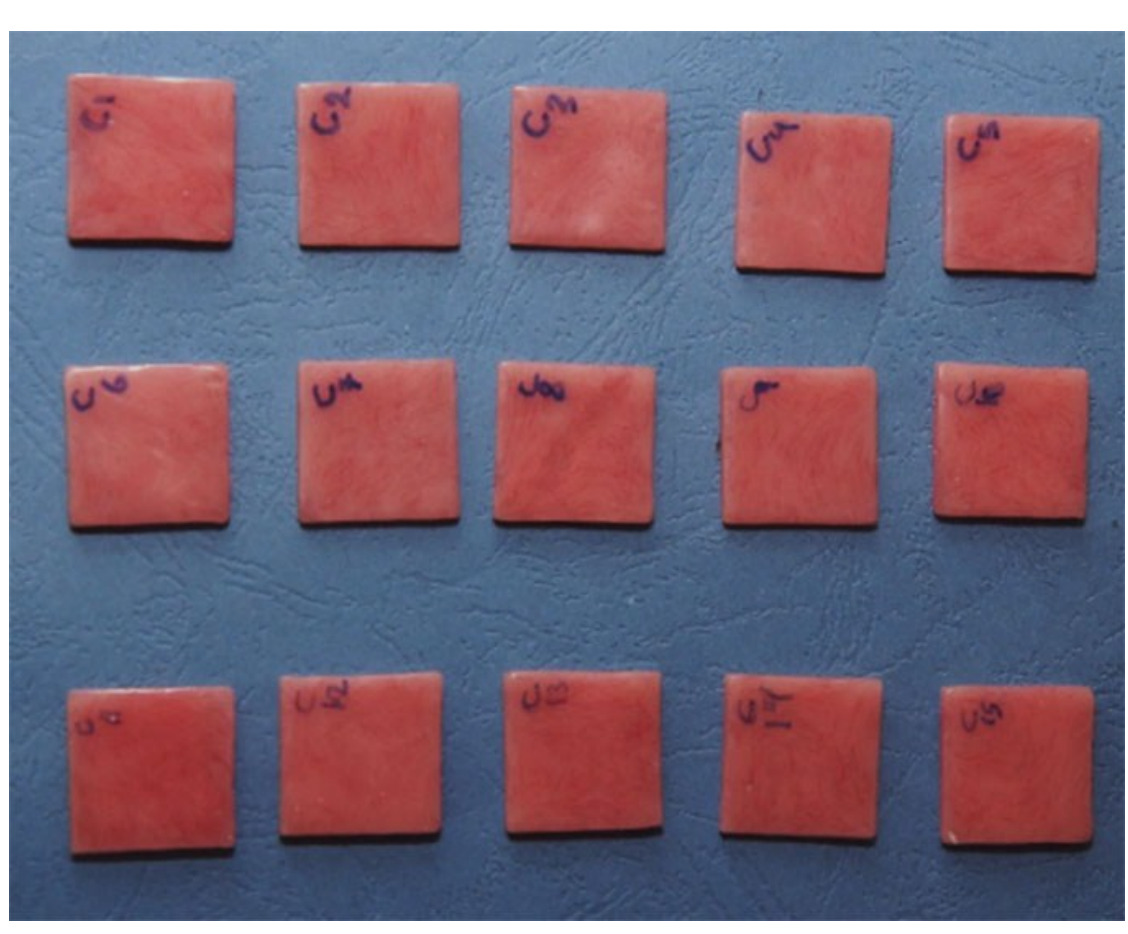

Figure 1 (C) Conventional heat-polymerized specimens 
